\title{
Mechanisms and Targets of Deep Brain Stimulation in Movement Disorders
}

\author{
Matthew D. Johnson, ${ }^{\dagger 1}$ Svjetlana Miocinovic, ${ }^{\ddagger 1}$ Cameron C. McIntyre, ${ }^{\dagger}$ and Jerrold L. Vitek ${ }^{\S}$ \\ ${ }^{\dagger}$ Departments of Biomedical Engineering and ${ }^{\S}$ Neurosciences, Cleveland Clinic Foundation, Cleveland, Ohio 44195; and ${ }^{\ddagger}$ School \\ of Medicine, Case Western Reserve University, Cleveland, Ohio 44106
}

Summary: Chronic electrical stimulation of the brain, known as deep brain stimulation (DBS), has become a preferred surgical treatment for medication-refractory movement disorders. Despite its remarkable clinical success, the therapeutic mechanisms of DBS are still not completely understood, limiting opportunities to improve treatment efficacy and simplify selection of stimulation parameters. This review addresses three questions essential to understanding the mechanisms of DBS. 1) How does DBS affect neuronal tissue in the vicinity of the active electrode or electrodes? 2) How do these changes translate into therapeutic benefit on motor symptoms? 3) How do these effects depend on the particular site of stimulation? Early hypotheses proposed that stimulation inhibited neuronal activity at the site of stimulation, mimicking the outcome of ablative surgeries. Recent studies have challenged that view, suggesting that although somatic activity near the DBS electrode may exhibit substantial inhibition or complex modulation patterns, the output from the stimulated nucleus follows the DBS pulse train by direct axonal excitation. The intrinsic activity is thus replaced by high-frequency activity that is time-locked to the stimulus and more regular in pattern. These changes in firing pattern are thought to prevent transmission of pathologic bursting and oscillatory activity, resulting in the reduction of disease symptoms through compensatory processing of sensorimotor information. Although promising, this theory does not entirely explain why DBS improves motor symptoms at different latencies. Understanding these processes on a physiological level will be critically important if we are to reach the full potential of this powerful tool. Key Words: High-frequency stimulation, neuromodulation, electrophysiology, neurochemistry, computer modeling, imaging.

\section{INTRODUCTION}

Deep brain stimulation (DBS) is a highly effective surgical therapy for helping people with movement disorders re-establish control over their motor function. Much of its success has been based on long-term experiences with surgical ablation for managing hyperkinetic and hypokinetic states. ${ }^{1}$ These procedures not only provided the impetus to develop a stereotactic apparatus for targeting deep brain structures, ${ }^{2,3}$ but they also imparted critical knowledge of what brain regions are involved in the expression of motor signs for various movement disorders. ${ }^{4,5}$

Intraoperative electrical stimulation was recognized early on as an important prelesion targeting tool, capable of augmenting or suppressing motor signs

\footnotetext{
${ }^{1}$ Both authors contributed equally to the work.

Address correspondence and reprint requests to: Jerrold L. Vitek, M.D., Ph.D., Department of Neurosciences, Cleveland Clinic Foundation, 9500 Euclid Ave, NC30, Cleveland, OH 44195. E-mail: vitekj@ccf.org.
}

depending on the frequency and amplitude of stimulation. In 1960, Hassler et al. ${ }^{6}$ reported that low-frequency stimulation $(<25 \mathrm{~Hz})$ in the globus pallidus elicited contralateral tremor in parkinsonian patients, whereas high-frequency stimulation $(25 \mathrm{~Hz}-100 \mathrm{~Hz})$ applied to the same location suppressed tremor. Since then, similar stimulation-dependent effects have been reported in other nuclei and for other clinical indications (FIG. 1). DBS offers important advantages over the immutable effects of ablative procedures, including the reversibility of the surgical outcome and the ability to adjust stimulation parameters postoperatively to optimize therapeutic benefit for the patient while minimizing adverse side effects. ${ }^{7,8}$ Thousands of DBS implants are now performed each year for a growing number of movement disorders. ${ }^{9-11}$ Nonetheless, despite the clinical successes of DBS, we still lack a fully formulated theory for how DBS works. ${ }^{12-14}$

Since the inception of DBS as a clinical therapy, its mechanisms have been the focus of intense scientific 


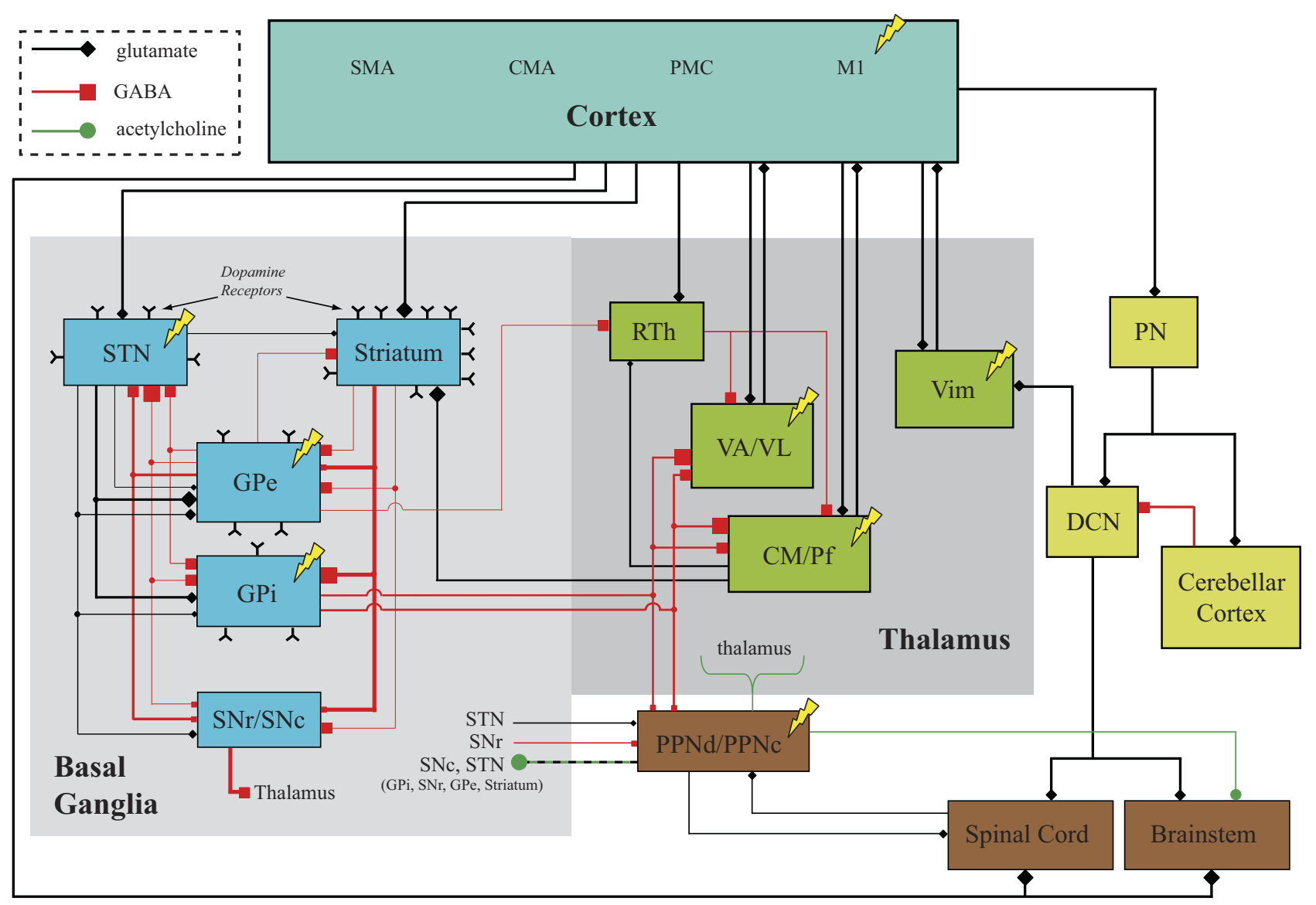

FIG. 1. For movement disorders, deep brain stimulation is an effective therapy that, similar to surgical ablation, encompasses several therapeutic targets within the sensorimotor network. DBS targets are indicated by lightning bolts. Line connection thicknesses within the basal ganglia network correspond to the relative proportion of a particular projection. Synaptic terminal shape sizes signify the degree of axonal branching of a particular cell type. Line color and terminal shapes represent the type of neurotransmitter involved in the signaling pathway (legend at top left for GABA, glutamate, and acetylcholine). CM = centromedian nucleus of thalamus; CMA = cingulate motor area; $\mathrm{DCN}=$ deep cerebellar nuclei; $\mathrm{GPe}=$ globus pallidus pars externa; $\mathrm{GPi}=$ globus pallidus pars interna; $\mathrm{M} 1=$ primary motor cortex; $\mathrm{Pf}=$ parafascicular nucleus of thalamus; $\mathrm{PMC}=$ premotor cortex; $\mathrm{PN}=$ pontine nuclei; PPNc = pedunculopontine nucleus pars compacta; PPNd = pedunculopontine nucleus pars dissipatus; RTh = reticular nucleus of thalamus; SMA = supplementary motor cortex; SNc = substantia nigra pars compacta; SNr = substantia nigra pars reticulata; STN = subthalamic nucleus; VA = ventroanterior thalamus; Vim = ventral intermediate nucleus of thalamus; VL = ventrolateral thalamus. Figure compiled from data in Pahapill and Lozano, ${ }^{81}$ Parent and Parent ${ }^{168}$, and Alexander et al. ${ }^{169}$

study and debate. This review integrates results from electrophysiological experiments, biochemical analyses, computer modeling, and imaging studies, to provide an up-to-date understanding of DBS mechanisms. The discussion focuses on three questions essential to understanding the mechanisms of DBS. 1) How does DBS affect individual neurons in, and axonal elements passing through, the region around the active electrode or electrodes? 2) How do these neural responses translate into observable benefit in motor symptoms? 3) How do these effects depend on the particular site of stimulation?

Significant progress has been made in recent years in addressing these questions, but there are notable gaps in the literature. Better understanding of the physiological processes underlying what makes DBS an effective therapy will allow us to improve the efficacy of current applications, simplify methods of optimizing stimulation parameters for patients currently receiving the therapy,${ }^{15,16}$ and provide the rationale for developing new applications and new technology.

\section{NEURAL RESPONSES TO DBS}

\section{Somatic activity in the stimulated nucleus}

The earliest hypotheses on DBS mechanisms attempted to reconcile the similarity in clinical outcome after a lesion and during DBS by proposing that highfrequency stimulation (HFS) inhibits neurons and decreases output from the stimulated site. ${ }^{717}$ Consistent with this hypothesis are several studies showing that HFS in either the subthalamic nucleus (STN) or globus pallidus pars interna (GPi) suppresses somatic activity around the stimulated electrode. ${ }^{18-27}$ For example, Meissner et al. ${ }^{27}$ recorded STN neuronal activity for 
several minutes before, during, and after HFS with parameters $(100 \mu \mathrm{A}$ amplitude, $130 \mathrm{~Hz}$ frequency, and 60 $\mu$ s pulse width) that improved contralateral rigidity in parkinsonian monkeys. In that study, therapeutic stimulation decreased the mean firing rate in the majority of STN neurons, from $19 \mathrm{~Hz}$ to $8 \mathrm{~Hz}$. They proposed that the decrease in mean firing rate resulted from resetting the firing probability of STN neurons by each stimulus pulse. Neurons resumed activity after approximately 3 ms following a stimulus pulse and returned to baseline after approximately $7 \mathrm{~ms}$. By stimulating at $130 \mathrm{~Hz}$, which corresponded to a 7.7-ms interpulse interval, these cells fired at their baseline rate for only a brief period of time, resulting in an overall reduction in mean firing rate. Bar-Gad et al. ${ }^{25}$ reported that HFS in the globus pallidus (GP) resulted in a similar time-locked response in $70 \%$ of the GP cells recorded adjacent to the stimulation electrode. The average firing pattern of these cells consisted of an initial inhibitory response, followed by two excitatory phases at $3 \mathrm{~ms}$ and $7 \mathrm{~ms}$. They also found that an additional $12 \%$ of neurons in the globus pallidus were completely inhibited over the stimulation period.

Because electrical stimulation is generally thought to excite neurons, the question then arises as to what mechanisms account for the resetting and overall reduction of somatic activity near the stimulated electrode? Several possibilities have been proposed, including depolarization block due to an increase in potassium current ${ }^{28}$ or an inactivation of sodium channels, ${ }^{29,30}$ presynaptic depression of excitatory afferents, ${ }^{31}$ and stimulation-induced activation of inhibitory afferents. ${ }^{32,33}$ Support for the depolarization block hypothesis comes primarily from in vitro experiments. Magariños-Ascone et al., ${ }^{34}$ for example, reported that STN cells in rat brain slices increased their instantaneous firing rate during the initial stimulation period, after which these neurons failed to respond. In an in vivo situation, however, depolarization block is unlikely. Multiple studies have shown that HFS reduced, but did not completely block, neuronal activity. ${ }^{19,22,27}$ Moreover, somatic inhibition could appear after a single stimulus pulse, ${ }^{18}$ and both inhibition and recovery from inhibition occurred at latencies consistent with GABAergic postsynaptic current kinetics. ${ }^{27}$ The fact that in vitro slices are often disconnected from their afferent inputs could explain the different results observed between the two experimental preparations.

Stimulus-evoked somatic inhibition may not apply to all neurons surrounding the active DBS electrodes. In vivo experiments indicate that a small number of STN neurons exhibit higher firing rates during STN HFS, which may result from activation of excitatory presynaptic terminals. ${ }^{22}$ Similarly, thalamic neurons in regions that receive predominantly excitatory afferents exhibit an increase in somatic activity during thalamic HFS. ${ }^{32 a}$ For cells exhibiting complex firing patterns during HFS, the delayed excitatory and inhibitory phases likely reflect a combination of intrinsic membrane dynamics and network effects. Hyperpolarization-activated cation ( $\mathrm{HCN})$ and low-threshold calcium (T-type) channel currents, for example, may be activated during HFS resulting in an excitatory time-locked rebound. ${ }^{31,33}$ The contribution of network and reentrant loops ${ }^{35}$ also warrants further investigation with in vivo experiments that incorporate local infusion of specific antagonists during HFS.

\section{Axonal output of the stimulated nucleus}

In the previous section, we presented evidence that, overall, HFS reduces somatic activity in the STN and GPi. This somatic activity may not, however, necessarily parallel the output of the stimulated nucleus. Indeed, several experimental studies suggest that output is increased from an ostensibly inhibited nucleus, ${ }^{36-38}$ bringing into question the mechanism underlying this paradoxical dissociation. One explanation argues that when a cell is exposed to extracellular stimulation, the stimulusinduced action potential initiates in the axon rather than in the cell body. A modeling study of thalamocortical neurons targeted by HFS found that the position of the neuron with respect to the electrode determined its output firing characteristics. ${ }^{39}$ Neurons close to the stimulation electrode had their spontaneous activity suppressed by activation of inhibitory presynaptic terminals, and their axons were directly activated. Axonal spike output thus became time-locked to the stimulus frequency. The thalamocortical models also predicted that, even though stimulation current was subthreshold for direct axonal activation of neurons positioned farther away from the electrode, the stimulus could activate nearby axonal afferents extending inhibitory collaterals that innervate distal neurons. As a result, neural output of these cells resembled their somatic activity.

It is exceptionally difficult to directly record axonal activity; nevertheless, axonal firing can be indirectly monitored by recording from cells receiving afferent input from the stimulated nucleus. Taking this approach, Hashimoto et al. ${ }^{37}$ demonstrated in parkinsonian nonhuman primates that neuronal firing rates in GPe and GPi increased in response to therapeutic STN HFS, suggesting increased output from STN (FIG. 2). For stimulation parameter settings that improved contralateral rigidity and bradykinesia, a majority of pallidal neurons also showed a consistent pattern of response: two peaks of increased activity in the post-stimulus time histogram, at $3 \mathrm{~min}$ and $6.5 \mathrm{~min}$. Surrounding the excitatory peaks were periods of inhibition, which were especially pronounced for GPi neurons. In contrast, during therapeutically ineffective stimulation, the overall firing rate and pattern of GPi activity did not change significantly. Comprehensive computer models of STN HFS in these monkeys confirmed that approximately $50 \%$ of model STN 

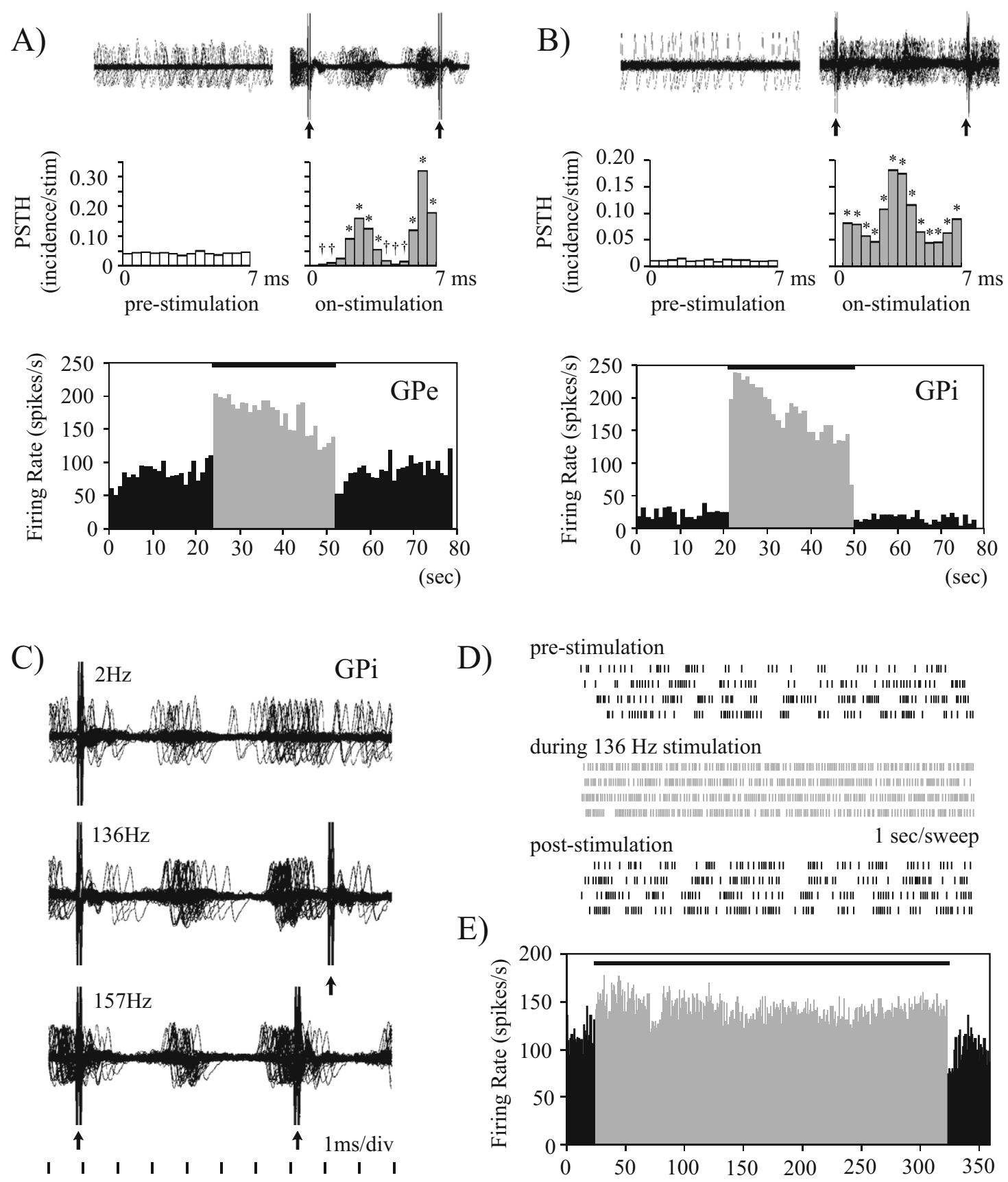
D) pre-stimulation

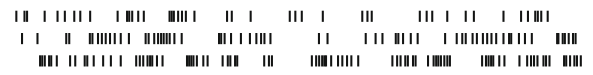

during $136 \mathrm{~Hz}$ stimulation

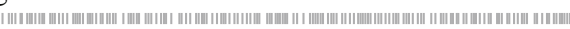

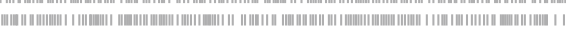
||⿴囗ก)

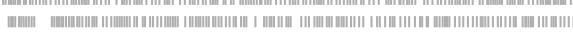

post-stimulation

$1 \mathrm{sec} / \mathrm{sweep}$

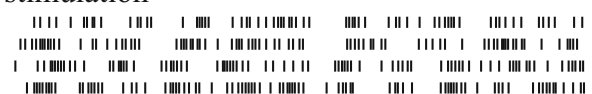

E)

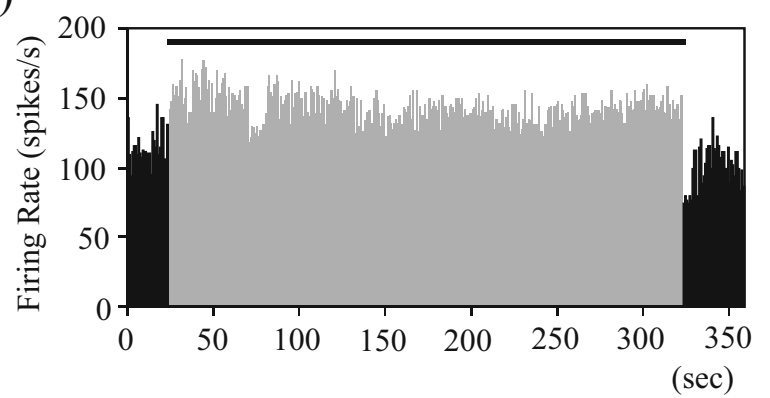

FIG. 2. High-frequency stimulation in the STN generates complex changes in pallidal spike activity (modified with permission from $\mathrm{J}$ Neurosci 2003;23:1916-1923). Examples of neuronal responses occurring during STN stimulation in a (A) GPe cell and (B) GPi cell of a parkinsonian monkey. The top traces show spike recordings of 100 sweeps made by triggering at 10-ms intervals in the pre-stimulation period (left) and by triggering on the stimulation pulse in the on-stimulation period (right). Middle plots display peri-stimulus time histograms (PSTHs) reconstructed from successive 7.0-ms time periods in the pre-stimulation period and from the interstimulus periods in the on-stimulation period. Bottom plots represent the mean firing rate calculated every second on the basis of the PSTH. * Significant increase at $p<0.01,{ }^{\dagger}$ significant decrease at $p<0.01$; Wilcoxon signed rank test. (C) Short-latency excitation was greater and more tightly coupled to each stimulation pulse during higher-frequency stimulation. Overlay of 50 sweeps of neuronal activity of a GPi cell during $2 \mathrm{~Hz}$ (top), $136 \mathrm{~Hz}$ (middle), and $157 \mathrm{~Hz}$ (bottom) stimulation at $3.0 \mathrm{~V}$. Each stimulation frequency is associated with excitation peaks at $2.5 \mathrm{~ms}$ to $4.0 \mathrm{~ms}$ and at $5.5 \mathrm{~ms}$ to $7.0 \mathrm{~ms}$ after onset of stimulation. (D) Raster scans of GPi neuronal activity showed that firing patterns changed from irregular with varying interspike intervals into a high-frequency regular pattern, with most interspike intervals occurring at $4 \mathrm{~ms}$ or $7 \mathrm{~ms}$ during stimulation at $136 \mathrm{~Hz}$, 3.0 V. (E) An example of the time course of the change in firing rate of a GPi neuron during prolonged 136- $\mathrm{Hz}$ STN stimulation. An increased mean discharge rate in this neuron was sustained during the 5-min stimulation period. 
axons were activated during therapeutic stimulation (i.e., their axonal output was entrained to at least $80 \%$ of the stimulus pulses). ${ }^{40}$ Furthermore, axonal activation of STN projection neurons was significantly higher for clinically effective than for clinically ineffective stimulation settings. These results indicate that therapeutic STN HFS activated subthalamo-pallidal projections and changed the discharge pattern of GPi neurons from an irregular to a more regular, stimulus-synchronized pattern of activity.

A complementary study by Kita et al. ${ }^{41}$ demonstrated that the late excitatory responses in GPe after STN stimulation were glutamatergic in origin, whereas the delayed inhibitory phases in GPi were products of GABAergic signaling from GPe. This study also showed more pronounced inhibitory phases in GPi than those observed in the Hashimoto et al. ${ }^{37}$ study. The relative importance of inhibitory GPe-GPi connections compared to excitatory STN-GPi connections in nonparkinsonian subjects (see the 1995 article by Calon et al., ${ }^{42}$ for example) stimulated with small electrodes and long pulses may have contributed to the observed differences. Positron emission tomography (PET) experiments in humans have confirmed that blood flow in the region of GPi increases during STN HFS, ${ }^{43}$ which is consistent with activation of output from the stimulated site. A functional MRI study also found an increase in blood oxygen level-dependent signal in GPi of patients undergoing STN HFS. ${ }^{44}$

The 'output activation' hypothesis appears to hold for other target nuclei as well. ${ }^{36,45-47}$ A study examining motor scores in parkinsonian monkeys during GPe HFS $^{48}$ found that therapeutic stimulation parameters led to a pronounced reduction in firing rate and bursting in $67 \%$ of the recorded STN neurons, whereas only $31 \%$ of STN neurons were significantly inhibited for nontherapeutic stimulation. In untreated monkeys, Anderson et al. ${ }^{36}$ reported that GPi HFS inhibited $77 \%$ of thalamic neurons, which is consistent with orthodromic activation of GABAergic projections. Montgomery ${ }^{45}$ described a similar reduction in thalamic neuronal activity in humans during GPi HFS with time-locked responses involving an overall suppression in the firing probability, except for a brief excitatory phase at $3.5 \mathrm{~ms}$ to $5 \mathrm{~ms}$. In a dystonic patient, Pralong et al. ${ }^{46}$ observed that GPi HFS induced thalamic inhibition only in a subpopulation of ventralis oralis anterior (Voa) thalamic neurons that exhibited intrinsically high firing rates and a low burst index. Voa neurons expressing lower firing rates and a higher burst index were unaffected by GPi HFS. Because these unaffected neurons were located primarily in the anterior and medial regions of the $\mathrm{Voa},{ }^{49}$ the disparity of thalamic responses could have reflected weak pallidal innervation. Alternatively, GPi HFS could have a less pronounced effect on Voa neurons with low $(3-6 \mathrm{~Hz})$ firing rates or with higher modulatory thresholds.
The inference of increased output to downstream nuclei is corroborated by evidence from neurochemical measurements. During STN HFS in human subjects with Parkinson's disease (PD), Stefani et al. ${ }^{50,51}$ detected an increase in pallidal cGMP, considered to be a secondary messenger in the glutamatergic signaling pathway, which was accompanied by improvement in clinical symptoms. Microdialysis studies during STN HFS in normal anesthetized rats detected elevated levels of 1) glutamate in both the substantia nigra pars reticulata $(\mathrm{SNr})$ and the GP (rat analog of primate $\mathrm{GPe}$ ), which is consistent with increased output from STN, ${ }^{52,53}$ and 2) GABA in the $\mathrm{SNr}$, which may be a secondary effect or a result of suprathreshold current spreading into pallidonigral fibers of passage. ${ }^{54}$ These studies have also shown that elevated GABA levels depend on the frequency of stimulation, closely mimicking the frequency-response curves reported in clinical applications of DBS. ${ }^{52}$

Boulet et al. ${ }^{55}$ suggested that neurochemical effects of HFS also depend on the amplitude of stimulation and whether or not the subject is parkinsonian. At high stimulation amplitudes (75-200 $\mu \mathrm{A})$, sufficient to evoke contralateral forelimb dyskinesias, STN HFS increased glutamate and GABA in the $\mathrm{SNr}$ of intact rats, but only glutamate in the $\mathrm{SNr}$ of 6-hydroxydopamine (6-OHDA) lesioned rats. At subthreshold stimulation amplitudes $(<60 \mu \mathrm{A})$ for these dyskinesias, GABA but not glutamate increased in 6-OHDA lesioned rats and no change was seen in intact rats. Together, these measurements are compatible with electrophysiological recordings showing elevated SNr activity with high-amplitude STN HFS and reduced activity with low-amplitude STN HFS. ${ }^{38}$

The different GABAergic responses observed for parkinsonian and normal rats are difficult to reconcile. Given the small size of the STN in rats and the large stimulation amplitudes applied with these experiments, one possibility is that current inadvertently activated adjacent GABAergic fibers of passage from the striatum or antidromically excited GABAergic axon collaterals from the $\mathrm{SNr}$ (or both). Antidromic activation of afferent cortical projections during STN HFS may have also affected cortical and subsequently striatofugal activity. ${ }^{41,56}$ Additionally, stimulation may have orthodromically activated GPe-STN projection neurons that extend inhibitory collaterals into $\mathrm{SNr}^{57}$ These considerations attest to the complex pattern of excitation and inhibition that is likely to emerge in response to stimulation and the importance of incorporating polysynaptic pathways and adjacent fiber tracts into the interpretation of experimental findings.

\section{Activation of fiber tracts of passage}

In considering therapeutic mechanisms of DBS, the primary focus has been on the response of neurons within the stimulated nucleus. However, stimulation currents sufficient for axonal activation can spread outside 
the borders of the anatomical target. This is especially true for the STN, which is a small nucleus surrounded by several major tracts of fibers. ${ }^{58}$ Pallidothalamic fibers within the lenticular fasciculus (LF), or H2 field of Forel, run dorsal to the STN and carry inhibitory fibers from the GPi to the thalamus. A computer modeling study of STN HFS in parkinsonian monkeys found that stimulation intensities, which were therapeutic for bradykinesia and rigidity, activated a significant number of these fibers. ${ }^{40}$ Plaha et al. ${ }^{59}$ have argued that current spreading into the zona incerta, a small nucleus dorsal to the LF, also contributed to the beneficial effects of STN HFS on parkinsonian symptoms. Likewise, the reduction of tremor with STN HFS has been hypothesized to stem from direct excitation of cerebellothalamic fibers coursing through the fields of Forel. ${ }^{60,61}$

High-frequency stimulation of the STN may directly activate nigrostriatal and pallidonigral fiber tracts and thus contribute to a therapeutic effect by modulating the release of dopamine. ${ }^{62-66}$ Although animal studies have shown a significant increase in striatal dopamine with STN HFS and have offered an attractive explanation for improvement of PD symptoms coincident with a reduction in antiparkinsonian medication, to date there is no evidence that a similar process occurs in humans. Several PET studies using $\left[{ }^{11} \mathrm{C}\right]$ raclopride to measure dopamine binding have failed to show changes during STN HFS, suggesting that the therapeutic effects of STN stimulation are not mediated by striatal dopamine release. ${ }^{67-69}$ However, advanced-stage PD patients have fewer SNc neurons available to release dopamine, and with PET imaging of such patients one may be less likely to observe a change in dopamine levels sufficient for detection. Future studies using microdialysis or voltammetric techniques in conjunction with behavioral analysis may help resolve this controversy. Another possibility is that the stimulation paradigms and electrodes used in the rodent experiments may be more disposed to current spreading beyond the borders of STN and, therefore, are more likely to have a higher proportion of nigrostriatal fibers directly activated.

In addition to the fibers passing adjacent to the target nucleus, stimulation currents may also activate fibers coursing through the target nucleus. The GPi, for instance, contains a rich set of collateralizing fibers that in turn target other nuclei. ${ }^{70}$ Anatomical tracing studies have found that approximately $40 \%$ of GPe cells send projections to the STN through the GPi. ${ }^{57}$ Thus, stimulating the GPi may influence the STN directly, by activating GPe GABAergic fibers of passage. In primates, nigrostriatal axons collateralize in both GPe and GPi, forming dense fiber bundles along the medullary laminae en route to the putamen. ${ }^{71,72}$ Although one study showed that stimulation in the entopeduncular nucleus (rat homolog of the primate GPi) had no significant effect on striatal dopamine release, ${ }^{73}$ the results may not translate to primates, which have significantly different pallidal anatomies from those in rodents. ${ }^{10}$ The potential therapeutic role of activating fiber bundles running near or within the target structure remains to be determined, but the potential for stimulating these fibers of passage should be taken into consideration when interpreting neural responses to DBS.

\section{THERAPEUTIC MECHANISMS OF DBS}

\section{Approaches to studying the mechanisms of DBS}

There are many experimental approaches to studying the mechanisms of DBS, as outlined in the previous section. Because methodological differences can affect observed responses, it is important to consider the state of the preparation (in vitro or in vivo; anesthetized or awake; normal or pathological), stimulation parameters (current amplitude is the most difficult to compare across studies), stimulation duration (milliseconds versus hours), and the type of stimulation electrode used, its relative size and exact location-all of which can affect the volume of tissue influenced by stimulation. Also, one cannot overemphasize the importance of a behavioral correlate in DBS experiments. Observed stimulation effects are relevant to therapeutic mechanisms of DBS only if they accompany improvement in disease symptoms. Valuable information may be obtained from experiments using brain slices, anesthetized, or naïve animals, but conclusions from these studies regarding the therapeutic mechanisms of DBS must be interpreted with caution. We have observed significantly different neuronal responses with stimulation parameters that did and did not produce a therapeutic effect. ${ }^{37}$

\section{Regularization of pathological activity}

A proposed mechanism of DBS that is consistent with an increase in neural output from the targeted region is that stimulation overrides pathological neuronal discharge by imposing a more regular effect on downstream nuclei. ${ }^{74,75}$ Both experimental ${ }^{37,76}$ and modeling ${ }^{77}$ studies have shown that HFS replaces intrinsic irregular activity with activity that is time-locked to the stimulus. Regularization of GPi firing by STN HFS appears to reduce the disorder (entropy) of neuronal signals (A. Dorval, personal communication) and restores the responsiveness of thalamocortical cells to synaptic inputs (e.g., sensorimotor information), despite increased inhibitory drive. $^{78}$

Frequencies greater than $100 \mathrm{~Hz}$ typically provide symptom relief and frequencies below $20 \mathrm{~Hz}$ often worsen symptoms, perhaps by adding spikes to an already irregular pattern of spontaneous firing or by promoting bursting behavior in downstream nuclei. Neurochemical studies support this claim, showing that low- 
frequency stimulation does not lead to the neurochemical and molecular changes seen with HFS. ${ }^{52,79}$ However, not all nuclei or clinical indications require stimulation at frequencies greater than $100 \mathrm{~Hz}$. DBS in the pedunculopontine nucleus (PPN), for example, is most effective at stimulation frequencies between $20 \mathrm{~Hz}$ and $60 \mathrm{~Hz}{ }^{80}$ PPN neurons exhibit lower baseline firing rates $(\sim 15 \mathrm{~Hz}$ on average) than those observed in other nuclei. ${ }^{81,82}$ In dystonic cases, in which pathological GPi firing rates are thought to be lower than in PD, therapeutic DBS frequencies may also be lower. ${ }^{83,84}$

There are two possible mechanisms by which stimulation at frequencies greater than a neuron's own spontaneous rate can override the neuron's intrinsic output. First, antidromic action potentials initiated in axon collaterals may collide with orthodromic soma- or dendriteinitiated spikes, thereby blocking the intrinsic irregular pattern of activity from being conducted down the axon. Second, antidromic invasion of the soma may prevent the cell from discharging spontaneously, because of the refractory period associated with such activity. In both cases, irregular activity would be replaced by a more regular pattern of discharge. Even though this tonic, high-frequency firing pattern is not considered normal, it is seemingly devoid of informational content. The resulting 'informational lesion' may thus prevent pathological activity from being transmitted and amplified within the sensorimotor network. ${ }^{77}$

Analysis of DBS experimental data supports the concept that neural pattern, rather than firing rate, is an important determinant of the pathologic state and the therapeutic effects seen with DBS. ${ }^{37,74,75,85}$ In addition to changes in mean rate and irregularity of neuronal discharge in the basal ganglia, certain movement disorders are also characterized by the development of rhythmic, oscillatory activity. ${ }^{86,87}$ Most notably in PD patients, synchronized bursting was present between the STN and the GPe ${ }^{88-90}$ in which oscillatory frequencies in the range of $15 \mathrm{~Hz}$ to $30 \mathrm{~Hz}$ (beta range) tended to predominate. ${ }^{91}$ After dopaminergic treatment (e.g., levodopa), the power of these oscillations in the GP attenuated. ${ }^{88} \mathrm{~A}$ similar effect in the GP was shown for clinically beneficial STN HFS parameter sets in humans. ${ }^{92}$ Experimental evidence has also suggested that STN HFS decreases neuronal burst activity in the STN and its target nuclei. ${ }^{20,27,37}$ As a result, reduction of pathological activity and its transmission through the network could be responsible for amelioration of motor symptoms during DBS.

\section{Effects on coactivation of competing motor programs}

If indeed DBS creates an 'informational lesion' in the stimulated tissue, what pathological information does DBS suppress? And, how might this relate to the observation that clinical benefits with DBS occur when a sufficient number of downstream neurons are modulated? One possibility, which accounts for motor signs of movement disorders, involves the theory of 'focused selection.' According to this theory, sensorimotor outputs from the GPi and the $\mathrm{SNr}$ work to inhibit competing motor programs that interfere with a desired set of movements. ${ }^{93,94}$ Abnormally correlated activity within the basal ganglia would then lead to coactivation of competing motor programs and undesirable activation of agonist and antagonist muscle activity. These pathological correlations would also result in an inability to facilitate appropriate motor sequences, leading to further breakdown in focused selection. ${ }^{95}$

Several studies have provided experimental evidence in support of this hypothesis. Parkinsonian nonhuman primates were shown to express significantly more multiple-joint receptive fields in the $\mathrm{GPi}^{96}$ and the thalamus $^{97,98}$ than did normal monkeys. During movement, most of these neurons were activated, whereas the activation-to-inactivation ratio was reversed for nonparkinsonian monkeys. ${ }^{99}$ In dystonia, experimental recordings showed enlarged receptive fields of dystonic joints in the somatosensory cortex, ${ }^{100}$ thalamus, ${ }^{101}$ and globus pallidus ${ }^{102,103}$ (but also see the 2003 article by Hutchison et al. $\left.{ }^{104}\right)$.

Are these single- and multiple-joint representations in the thalamus and cortex in any way transformed by DBS? And if so, does DBS directly induce these changes, or does it instead facilitate compensatory mechanisms that indirectly re-establish 'normal' receptive fields along the thalamocortical pathway? Although these questions remain unanswered, it is likely that suprathreshold currents generated during therapeutic DBS spread a few millimeters into tissue ${ }^{105}$ and thus simultaneously affect multiple motor processes or motor representations. In the sensory and motor cortex, for instance, repetitive electrical stimulation is known to induce receptive field plasticity of the sensorimotor representation. ${ }^{106}$ Similarly, ablation of a particular sensorimotor representation in the cortex can trigger a functional reorganization of the surrounding nuclei to compensate for the lesion. ${ }^{107}$ It is also possible that neuronal populations adjacent to a DBS electrode, but not directly affected by the stimulation, reorganize their intrinsic functionality. Studies examining receptive field stability in response to HFS may shed some light on such hypotheses of compensatory mechanisms enabled by therapeutic stimulation.

\section{Therapeutic latencies during DBS onset and with cessation}

Stimulation may induce both short-term and long-term changes in network activity. This is exemplified by the period of time necessary to achieve full reduction of symptoms once stimulation is initiated and the prolonged 

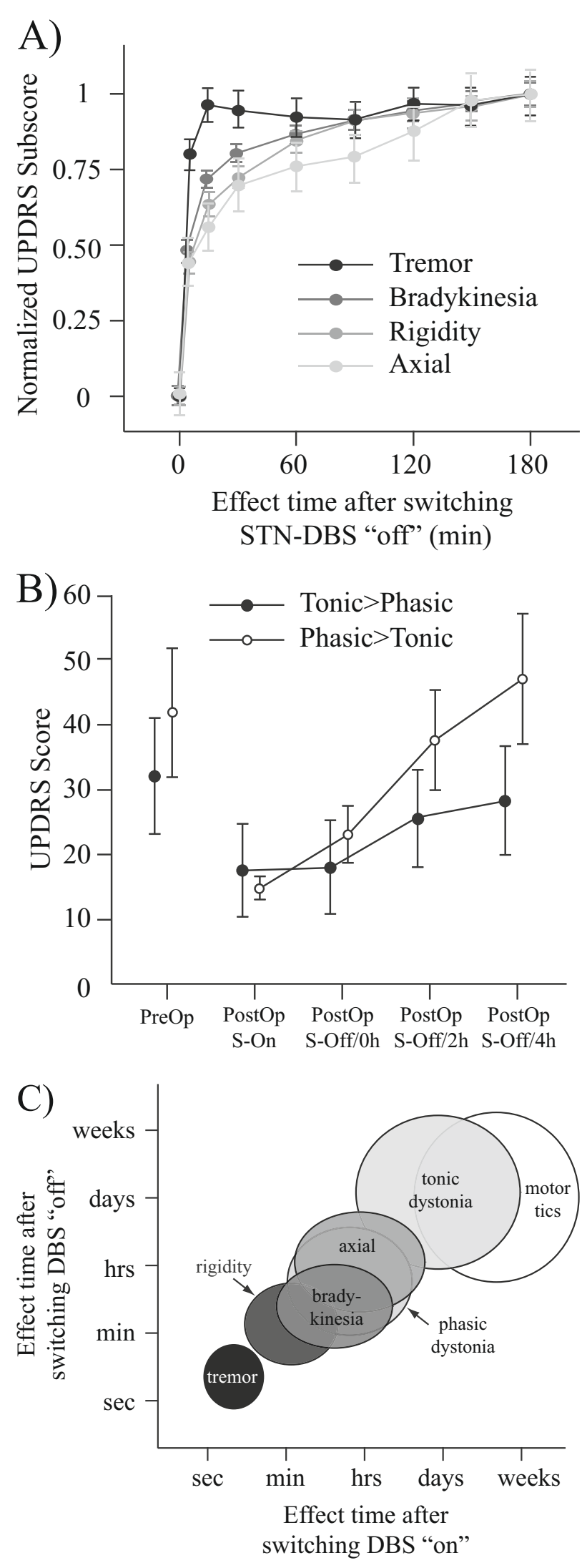

FIG. 3. DBS produces therapeutic effects with latencies that depend on the motor sign and the movement disorder. (A) Unified Parkinson's Disease Rating Scale (UPDRS) motor scores were evaluated after turning off STN DBS in 30 PD patients. Whereas tremor returned almost instantly, bradykinesia and rigidity latencies took approximately $30 \mathrm{~min}$ to deteriorate to preoperative 'off' scores, and axial symptoms continued to worsen over the course of the assessment period (modified with permission from Neurology 2003;60:78-81). (B) Unified Dystonia Rating Scale (UDRS) scores were evaluated after turning off GPi DBS in four patients with predominantly tonic dystonia and in another four patients who exhibited mainly phasic dystonia. Whereas phasic movements returned within 4 hours, tonic posturing did not fully return to a preoperative level during the assessment period (with permission from Journal Neurology, Neurosurgery, and Psychiatry 2007;78:318-320 ${ }^{170}$ ). (C) The divergence of therapeutic latencies following stimulation onset and cessation for various motor signs suggests that multiple mechanisms may account for the beneficial effects of DBS. 
There is mounting evidence that the mechanisms underlying the therapeutic latency may depend on the DBS target and parameters of stimulation. Vitek et al. ${ }^{47}$ reported that improvement in bradykinesia in PD patients occurred within seconds for GPe HFS, but the equivalent therapeutic effects took half a minute or more for GPi HFS, and they were preceded by a period of aggravated symptoms. In that study, GPe HFS at times induced dyskinesias that would start in the hand and over minutes spread from the upper extremities to the leg. Wu et al. ${ }^{24}$ reported that the latency of onset for dyskinesia suppression during GPi HFS decreased from $5 \mathrm{~s}$ to $1 \mathrm{~s}$ as the frequency of stimulation increased from 80 to $100 \mathrm{~Hz}$. Higher frequency stimulation (185 versus $135 \mathrm{~Hz})$ also appeared to decrease the therapeutic latency on rest tremor in PD patients. ${ }^{115}$ For motor signs that take days to weeks to improve following onset of stimulation and to develop following cessation of stimulation, the mechanisms that underlie these delays and the effects of varying stimulation parameter settings have not yet been investigated in detail.

\section{Variability in long-term outcome}

In some patients, motor symptoms may take many weeks to return after a period of chronic DBS, whereas in others the same symptoms reappear almost immediately after the neurostimulator is turned off. Lozano ${ }^{116}$ reported that tremor patients responded differently to Vim HFS. In $40 \%$ of patients, the mere implantation of the DBS system led to a significant reduction in tremor, and stimulation added additional benefit. Other patients (30\%) responded well to DBS initially, but developed a tolerance to the therapy over time. Remarkably, the remaining group of patients showed good benefit from DBS and eventually no longer needed to turn on the neurostimulator. For some DBS patients with dystonia, discontinuing stimulation resulted in a clinical rebound effect with acutely severe symptoms, ${ }^{109,117,118}$ whereas in other patients motor signs took hours, days, months, and in some cases years to return (B. Walter, personal communication). Although it is possible that stimulation could form a functional lesion in the tissue surrounding the active electrode contact or contacts, post mortem histology of DBS patients does not support this argument. ${ }^{19,120}$

What then accounts for this variability in long-term outcome? Yianni et al. ${ }^{109}$ speculated that the pathological low-frequency oscillations observed in patients with tremor, familial myoclonic dystonia, parkinsonian dyskinesias, and multiple sclerosis could promote axonal sprouting. They proposed that long-term HFS in certain nuclei might have reversed these pathological connections and thus allowed the network to resynchronize on normal rhythms. In support of this prediction, thalamocortical projection neurons displayed reorganized synap- tic connections for at least 1 year following a lesion in the $\mathrm{GPi}$ and $\mathrm{SNr},{ }^{121}$ with different effects on each GABAergic subtype. ${ }^{122}$ The latter finding is particularly noteworthy, in that $\mathrm{GABA}_{\mathrm{A}}$ and $\mathrm{GABA}_{\mathrm{B}}$ receptor densities in GPi are known to be abnormal in PD patients with levodopa-induced dyskinesias. ${ }^{123}$ Is it possible that axonal sprouting or synaptic plasticity, or both, are more tractable for certain patients or for certain DBS targets?

Others have hypothesized that HFS may be neuroprotective. ${ }^{124-126}$ In monkeys, several weeks of continuous STN HFS, preceding or following systemic injection of the dopaminergic neurotoxin 1-methyl-4-phenyl-1,2,3,6tetrahydropyridine (MPTP), resulted in $20 \%$ more tyrosine hydroxylase-positive $\left(\mathrm{TH}^{+}\right)$cells in the ipsilateral SNc. Similarly, kainic acid lesions of the STN appeared to have a protective effect on dopaminergic SNc neurons during subsequent injections of the neurotoxins 6-OHDA in rats ${ }^{127}$ and MPTP in monkeys. ${ }^{124}$ STN ablation after injection of these neurotoxins could also recover damaged dopaminergic neurons in the $\mathrm{SNc}$; however, when the DBS implant or injection volume extended into fibers of passage surrounding the STN, a notable reduction in $\mathrm{TH}^{+} \mathrm{SNc}$ cells occurred, which may reflect nigrostriatal axotomy. ${ }^{125}$ The authors of these studies speculated that the neuroprotective effects resulted from a reduction in glutamate excitotoxicity by limiting STN input into SNc. Although this hypothesis is not congruent with evidence of increased output activity during DBS, other mechanisms may explain their results, including the release of neurotrophic factors or stimulation of GABAergic fibers of passage that innervate the SNc.

\section{THERAPEUTIC TARGETS OF DBS}

\section{Why so many targets?}

Remarkably, the clinical benefits of DBS can be generated by targeting any one of a number of different regions in the brain, which emphasizes the role of network malfunction in movement disorders (FIG. 1) (see also other reviews of DBS elsewhere in this issue ${ }^{128-131}$ ). The primary targets of DBS for PD include the sensorimotor STN and GPi, ${ }^{132}$ and recent studies suggest that the PPN ${ }^{80} \mathrm{GPe},{ }^{47}$ and motor cortex ${ }^{133}$ are also effective targets. For most dystonias, the posteroventral GPi is now the preferred site of stimulation. ${ }^{12}$ The STN ${ }^{134,135}$ has also garnered some attention, and the posterior part of the ventrolateral thalamic nucleus (VLp) seems to be especially beneficial for patients with secondary dystonias. ${ }^{136}$ The Vim nucleus of the thalamus continues to be the primary target for essential tremor, ${ }^{137}$ although stimulation near the STN may also improve essential tremor and both STN and GPi DBS improve the tremor associated with PD. ${ }^{61,138}$ At least three regions have been targeted for Tourette syndrome, including the centromedian-parafascicular nucleus, ${ }^{113,139,140}$ anterior 
$\mathrm{GPi},{ }^{113,141,142}$ and anterior limb of the internal capsule. ${ }^{143}$ Given the multiplicity of effective stimulation targets, the question naturally arises whether the therapeutic mechanisms are the same. Or, to put it another way, are the compensatory network processes enabled by DBS identical for each target?

Several recording and imaging studies indicate that the cortical responses to STN HFS and GPi HFS differed for patients performing a movement-related task, even though no observable differences were apparent in task performance. Devos et al. ${ }^{144,145}$ reported that in a series of PD patients both STN HFS and GPi HFS reduced pathological desynchronization over premotor cortex and increased desynchronization over primary motor cortex during movement execution. During movement planning stages, however, GPi HFS did not facilitate an increase in primary motor cortex desynchronization but STN HFS did. ${ }^{144}$

Comparison of PET data on responses between STN HFS and GPi HFS suggested that clinically effective stimulation of both targets led to supplementary motor cortex and cingulate cortex activation during a joystick task. ${ }^{146}$ STN HFS produced higher cortical activation in general, however, and especially over the dorsolateral prefrontal cortex (DLPFC). Indeed, anatomical tracings have shown that $\mathrm{STN}$ neurons project to $\mathrm{SNr}$, which in turn target the DLPFC through the nigral-receiving area of thalamus. ${ }^{147}$ Nonetheless, it seems plausible that GPi HFS could have antidromically activated STN projections collateralizing in both the $\mathrm{GPi}$ and the $\mathrm{SNr}$ and thus indirectly affected the DLPFC.

Future studies with larger patient groups are warranted to determine whether different cortical responses evoked by STN HFS and GPi HFS are simply an epiphenomenon or, alternatively, reflect different compensatory mechanisms. Such studies in patients with PD should also take into account the improvement in motor symptoms produced by each site, relative to each patient's response to medication and the lead location within each target, to ensure that a reasonable comparison can be made. Well-placed leads in one structure compared with poorly placed leads in another will provide little insight and serve no useful purpose.

\section{Targets within a target: the concept of motor subcircuits}

Conventional thinking with DBS lead implantation is to place at least one electrode contact within the sensorimotor territory of the target nucleus. ${ }^{13}$ According to anatomical and electrophysiological studies, however, these sensorimotor regions are further demarcated into segregated, reentrant motor subcircuits with different subcortical-cortical projections. Hoover and Strick $^{148,149}$ showed that injection of trans-synaptic anatomical tracers into either the arm region of the motor cortex (MC) or the supplementary motor area (SMA) labeled different subregions of the sensorimotor GPi. Similarly, electrical stimulation of the MC in awake monkeys modulated neuronal activity in the posteroventral globus pallidus related to the execution of movement, whereas SMA stimulation modulated neurons in the anterodorsal pallidum associated with the planning of movement. ${ }^{150,151}$

Recent DBS studies examining therapeutic outcomes of stimulating specific subregions of the STN and GPi provide preliminary evidence that targeting multiple motor subcircuits is necessary to improve the various motor signs of PD. For STN HFS settings that improve parkinsonian symptoms, PET imaging showed that both MC and SMA activity were reduced at rest, whereas the SMA, superior parietal cortex, and cerebellum were activated during movement. ${ }^{152}$

Three independent studies observed that monopolar HFS through electrode contacts in the ventral GPi significantly improved rigidity and levodopa-induced dyskinesias, and at times worsened bradykinesia. ${ }^{153-155} \mathrm{On}$ the other hand, stimulation of the proximal contacts putatively within the dorsal GPi led to improvement in bradykinesia and rigidity, but occasionally produced dyskinesias at higher voltages. These studies were unable to quantify the extent of current spread in each patient, making it unclear what cellular substrates were actually modulated for each stimulation paradigm. In fact, based on the $10.5-\mathrm{mm}$ length of the lead over which the contacts extended, the dorsal contacts that relieved akinesia and at times produced dyskinesia were likely in the GPe, not the GPi. ${ }^{47}$ Additionally, the worsening of bradykinesia observed with stimulation in more ventral regions of the GPi could have resulted from activation of adjacent corticospinal tract fibers. ${ }^{156}$ Future studies will need to incorporate higher resolution imaging techniques, as well as computational models of current spread (on a patientspecific basis), to help identify what subregion or subregions underlie the clinical benefits of DBS.

\section{What to avoid: targets that lead to undesirable side effects}

Stimulation current spreading into regions adjacent to the DBS target has been shown to produce undesirable sensorimotor side effects, including paresthesias, speech difficulties, dystonias, dyskinesias, and contractile movements. The mechanisms underlying certain side effects are fairly well understood. For example, activation of the corticospinal tract within the internal capsule causes contralateral muscle contractions. ${ }^{157,158}$

A recent computer modeling study described promising results in the prediction of current spread during DBS. ${ }^{159}$ In these experiments, the locations of electrode contacts were reconstructed from postoperative MRI data, and a three-dimensional brain atlas was warped to 
the patient's MRI to identify anatomical structures and their position with respect to the stimulated electrode or electrodes. The patient-specific volume of tissue activated (VTA) was constructed using theoretical models of the DBS voltage field and axonal responses to extracellular stimulation. The patient was clinically evaluated with electromyography at various stimulation parameter settings. The model generated VTA values that accurately predicted the spread of stimulation into the corticospinal tract for stimulus parameters that generated electromyographic responses. Other sensorimotor side effects, however, are not as well understood. Worsening of dyskinesia or dystonia can appear during initial DBS programming sessions, but these symptoms decline after several hours of continuous stimulation. ${ }^{160}$

Deep brain stimulation can generate cognitive side effects as well, including mood changes, ${ }^{161}$ depression, ${ }^{162}$ decreased working memory performance, ${ }^{163,164}$ impulsivity, ${ }^{165}$ and hallucinations. ${ }^{166}$ One explanation for the emergence of such cognitive side effects is that suprathreshold currents spread into nonmotor regions within the basal ganglia and thalamocortical networks. ${ }^{13}$ Stimulation of the substantia nigra pars reticulata, for instance, was shown to evoke acute feelings of sadness in some patients. ${ }^{162}$ This side effect has not been consistent in all cases, however, and the question arises as to whether certain DBS patients have the pathophysiology of a cognitive disorder, but do not fully express the symptoms until DBS perturbs the underlying circuitry. Additional studies are clearly needed to examine the mechanisms by which sensorimotor and cognitive side effects occur with DBS, which may then provide the rationale for better ways to avoid generating them.

\section{Future targets and modalities for DBS in movement disorders}

Deep brain stimulation by any account has been a remarkably successful therapy for movement disorders, yet there remain notable opportunities for improvement on a patient-specific basis. Given the relatively small size of certain targets (such as the STN) and the complexity of others (such as the PPN), there is a specific need to develop more advanced DBS electrode systems and stimulation paradigms. DBS leads with directionally segmented electrodes instead of cylindrical electrodes may facilitate current steering away from regions involved in the generation of side effects. Advanced stimulation patterns with multiple independent current sources may also provide better targeting of the neural elements underlying the clinical benefit. Along these lines, stimulating multiple regions simultaneously, or with interleaved pulses (for example, GPi/STN or GPe/GPi), may impart more robust improvement of all motor symptoms.

Our growing understanding of the physiological mechanisms of DBS will likely lead to the development of closed-loop systems that use the brain's electrical or chemical activity as a feedback signal to adjust stimulation parameters dynamically to achieve an optimal level of therapeutic effect and conserve battery life of the neurostimulator. Many movement disorders also involve cognitive and autonomic dysfunction, which are not directly treated by current DBS approaches (see the 2004 article by Braak et al., ${ }^{167}$ for example). Future DBS trials may look to treat these nonmotor symptoms by delivering stimulation to other regions of the brain.

\section{CONCLUSIONS}

Early hypotheses on DBS mechanisms proposed that stimulation inhibited neuronal activity at the site of stimulation, imitating the effects of surgical ablation. Recent studies have challenged that view, suggesting that, although somatic activity near the DBS electrode may be suppressed, HFS increases and regularizes the output from the stimulated nucleus by directly activating axons of local projection neurons. It now appears that suprathreshold currents spreading into regions comprised of axonal fibers passing near or through the target structure as well as surrounding nuclei may also contribute to the beneficial effects of DBS. Together, the stimulation-induced regularization of neuronal output patterns is thought to prevent transmission of pathologic bursting and oscillatory activity within the basal gangliathalamocortical network, thereby enabling compensatory mechanisms that facilitate normal movements. This theory, however, does not entirely explain why therapeutic latencies differ between motor symptoms, nor why the reemergence of motor symptoms after DBS is turned off differs among patients. Understanding these processes on a physiological level will be critically important if we are to reach the full potential of DBS as a surgical therapy and will in turn undoubtedly lead us to technological and clinical advancements in the treatment of other neurological disorders.

Acknowledgments: This work was supported by grants from the National Institutes of Health, National Institute of Neurological Disorders and Stroke (NS037019 and NS047388).

\section{REFERENCES}

1. Gross R. What happened to posteroventral pallidotomy for Parkinson's disease and dystonia? Neurotherapeutics 2008;5:281293.

2. Hassler R, Riechert T. A special method of stereotactic brain operation. Proc R Soc Med 1955;48:469-470.

3. Spiegel EA, Wycis HT, Marks M, Lee AJ. Stereotaxic apparatus for operations on the human brain. Science 1947;106:349-350.

4. Spiegel EA, Wycis HT. Thalamotomy and pallidotomy for treatment of choreic movements. Acta Neurochir (Wien) 1952;2:417422 .

5. Meyers R. Surgical experiments in the therapy of certain "extra- 
pyramidal" diseases: a current evaluation. Acta Psychiatr Neurol Suppl 1951; 67:1-42.

6. Hassler R, Riechert T, Mundinger F, Umbach W, Ganglberger JA. Physiological observations in stereotaxic operations in extrapyramidal motor disturbances. Brain 1960;83:337-350.

7. Benabid AL, Pollak P, Louveau A, Henry S, de Rougemont J. Combined (thalamotomy and stimulation) stereotactic surgery of the VIM thalamic nucleus for bilateral Parkinson disease. Appl Neurophysiol 1987;50:344-346.

8. Siegfried J, Lippitz B. Chronic electrical stimulation of the VLVPL complex and of the pallidum in the treatment of movement disorders: personal experience since 1982. Stereotact Funct Neurosurg 1994;62:71-75.

9. Kringelbach ML, Jenkinson N, Owen SL, Aziz TZ. Translational principles of deep brain stimulation. Nat Rev Neurosci 2007;8: 623-635.

10. Perlmutter JS, Mink JW. Deep brain stimulation. Annu Rev Neurosci 2006;29:229-257.

11. Wichmann T, Delong MR. Deep brain stimulation for neurologic and neuropsychiatric disorders. Neuron 2006;52:197-204.

12. Liu Y, Postupna N, Falkenberg J, Anderson ME. High frequency deep brain stimulation: what are the therapeutic mechanisms? Neurosci Biobehav Rev 2008;32:343-3516.

13. Sudhyadhom A, Bova FJ, Foote KD, Rosado CA, Kirsch-Darrow L, Okun MS. Limbic, associative, and motor territories within the targets for deep brain stimulation: potential clinical implications. Curr Neurol Neurosci Rep 2007;7:278-289.

14. McIntyre CC, Savasta M, Walter BL, Vitek JL. How does deep brain stimulation work? Present understanding and future questions. J Clin Neurophysiol 2004;21:40-50.

15. Volkmann J, Herzog J, Kopper F, Deuschl G. Introduction to the programming of deep brain stimulators. Mov Disord 2002;17 Suppl 3:S181-S187.

16. Hunka K, Suchowersky O, Wood S, Derwent L, Kiss ZH. Nursing time to program and assess deep brain stimulators in movement disorder patients. J Neurosci Nurs 2005;37:204-210.

17. Tóth S, Tomka I. Responses of the human thalamus and pallidum to high frequency stimulations. Confin Neurol 1968;30:17-40.

18. Filali M, Hutchison WD, Palter VN, et al. Stimulation-induced inhibition of neuronal firing in human subthalamic nucleus. Exp Brain Res 2004;156:274-281.

19. Welter ML, Houeto JL, Bonnet AM, et al. Effects of high-frequency stimulation on subthalamic neuronal activity in parkinsonian patients. Arch Neurol 2004;61:89-96.

20. Shi LH, Luo F, Woodward DJ, Chang JY. Basal ganglia neural responses during behaviorally effective deep brain stimulation of the subthalamic nucleus in rats performing a treadmill locomotion test. Synapse 2006;59:445-457.

21. Benazzouz A, Gao DM, Ni ZG, Piallat B, Bouali-Benazzouz R, Benabid AL. Effect of high-frequency stimulation of the subthalamic nucleus on the neuronal activities of the substantia nigra pars reticulata and ventrolateral nucleus of the thalamus in the rat. Neuroscience 2000;99:289-295.

22. Tai CH, Boraud T, Bezard E, Bioulac B, Gross C, Benazzouz A. Electrophysiological and metabolic evidence that high-frequency stimulation of the subthalamic nucleus bridles neuronal activity in the subthalamic nucleus and the substantia nigra reticulata. FASEB J 2003;17:1820-1830.

23. Dostrovsky JO, Levy R, Wu JP, Hutchison WD, Tasker RR, Lozano AM. Microstimulation-induced inhibition of neuronal firing in human globus pallidus. J Neurophysiol 2000;84:570-574.

24. Wu YR, Levy R, Ashby P, Tasker RR, Dostrovsky JO. Does stimulation of the GPi control dyskinesia by activating inhibitory axons? Mov Disord 2001;16:208-216.

25. Bar-Gad I, Elias S, Vaadia E, Bergman H. Complex locking rather than complete cessation of neuronal activity in the globus pallidus of a 1-methyl-4-phenyl-1,2,3,6-tetrahydropyridinetreated primate in response to pallidal microstimulation. J Neurosci 2004;24:7410-7419.

26. Boraud T, Bezard E, Bioulac B, Gross C. High frequency stimulation of the internal globus pallidus (GPi) simultaneously improves parkinsonian symptoms and reduces the firing frequency of GPi neurons in the MPTP-treated monkey. Neurosci Lett 1996;215:17-20.

27. Meissner W, Leblois A, Hansel D, et al. Subthalamic high frequency stimulation resets subthalamic firing and reduces abnormal oscillations. Brain 2005;128:2372-2382.

28. Shin DS, Samoilova M, Cotic M, Zhang L, Brotchie JM, Carlen PL. High frequency stimulation or elevated $\mathrm{K}^{+}$depresses neuronal activity in the rat entopeduncular nucleus. Neuroscience 2007; 149:68-86.

29. Benazzouz A, Piallat B, Pollak P, Benabid AL. Responses of substantia nigra pars reticulata and globus pallidus complex to high frequency stimulation of the subthalamic nucleus in rats: electrophysiological data. Neurosci Lett 1995;189:77-80.

30. Beurrier C, Bioulac B, Audin J, Hammond C. High-frequency stimulation produces a transient blockade of voltage-gated currents in subthalamic neurons. J Neurophysiol 2001;85: $1351-1356$

31. Anderson TR, Hu B, Iremonger K, Kiss ZH. Selective attenuation of afferent synaptic transmission as a mechanism of thalamic deep brain stimulation-induced tremor arrest. J Neurosci 2006; 26:841-850.

32. Dostrovsky JO, Lozano AM. Mechanisms of deep brain stimulation. Mov Disord 2002;17 Suppl 3:S63-S68.

32a.Agnesi F, Lin J, Goerss SJ, Sieck GC, Stead M, Lee KH. Resolving local extracellular unit activity during deep brain stimulation at a site of stimulation in human patients. Soc Neurosci Abstr 2007;414:18 (abstract).

33. Chan CS, Shigemoto R, Mercer JN, Surmeier DJ. HCN2 and HCN1 channels govern the regularity of autonomous pacemaking and synaptic resetting in globus pallidus neurons. J Neurosci 2004;24:9921-9932.

34. Magariños-Ascone C, Pazo JH, Macadar O, Buño W. High-frequency stimulation of the subthalamic nucleus silences subthalamic neurons: a possible cellular mechanism in Parkinson's disease. Neuroscience 2002;115:1109-1117.

35. Montgomery EB Jr. Dynamically coupled, high-frequency reentrant, non-linear oscillators embedded in scale-free basal gangliathalamic-cortical networks mediating function and deep brain stimulation effects. Nonlinear Studies 2004;11:385-421.

36. Anderson ME, Postupna N, Ruffo M. Effects of high-frequency stimulation in the internal globus pallidus on the activity of thalamic neurons in the awake monkey. J Neurophysiol 2003;89: $1150-1160$

37. Hashimoto T, Elder CM, Okun MS, Patrick SK, Vitek JL. Stimulation of the subthalamic nucleus changes the firing pattern of pallidal neurons. J Neurosci 2003;23:1916-1923.

38. Maurice N, Thierry AM, Glowinski J, Deniau JM. Spontaneous and evoked activity of substantia nigra pars reticulata neurons during high-frequency stimulation of the subthalamic nucleus. J Neurosci 2003;23:9929-9936.

39. McIntyre CC, Grill WM, Sherman DL, Thakor NV. Cellular effects of deep brain stimulation: model-based analysis of activation and inhibition. J Neurophysiol 2004;91:1457-1469.

40. Miocinovic S, Parent M, Butson CR, et al. Computational analysis of subthalamic nucleus and lenticular fasciculus activation during therapeutic deep brain stimulation. J Neurophysiol 2006; 96:1569-1580.

41. Kita H, Tachibana Y, Nambu A, Chiken S. Balance of monosynaptic excitatory and disynaptic inhibitory responses of the globus pallidus induced after stimulation of the subthalamic nucleus in the monkey. J Neurosci 2005;25:8611-8619.

42. Calon F, Goulet M, Blanchet PJ, et al. Levodopa or D2 agonist induced dyskinesia in MPTP monkeys: correlation with changes in dopamine and $\mathrm{GABA}_{\mathrm{A}}$ receptors in the striatopallidal complex. Brain Res 1995;680:43-52.

43. Hershey T, Revilla FJ, Wernle AR, et al. Cortical and subcortical blood flow effects of subthalamic nucleus stimulation in PD. Neurology 2003;61:816-821.

44. Jech R, Urgosik D, Tintera J, et al. Functional magnetic resonance imaging during deep brain stimulation: a pilot study in four patients with Parkinson's disease. Mov Disord 2001;16:11261132. 
45. Montgomery EB Jr. Effects of GPi stimulation on human thalamic neuronal activity. Clin Neurophysiol 2006;117:2691-2702.

46. Pralong E, Debatisse D, Maeder M, Vingerhoets F, Ghika J, Villemure JG. Effect of deep brain stimulation of GPI on neuronal activity of the thalamic nucleus ventralis oralis in a dystonic patient. Neurophysiol Clin 2003;33:169-173.

47. Vitek JL, Hashimoto T, Peoples J, DeLong MR, Bakay RA. Acute stimulation in the external segment of the globus pallidus improves parkinsonian motor signs. Mov Disord 2004;19:907915.

48. Zhang J, Russo GS, Chen XX, Hashimoto T, Elder CM, Vitek JL. Deep brain stimulation of monkey globus pallidus externus in experimental parkinsonism. Soc Neurosci Abstr 2003:273.12(abstract).

49. Raeva S, Vainberg N, Dubinin V. Analysis of spontaneous activity patterns of human thalamic ventrolateral neurons and their modifications due to functional brain changes. Neuroscience 1999;88:365-376.

50. Stefani A, Fedele E, Galati S, et al. Subthalamic stimulation activates internal pallidus: evidence from cGMP microdialysis in PD patients. Ann Neurol 2005;57:448-452.

51. Stefani A, Fedele E, Galati S, et al. Deep brain stimulation in Parkinson's disease patients: biochemical evidence. J Neural Transm Suppl 2006:401-408.

52. Windels F, Bruet N, Poupard A, Feuerstein C, Bertrand A, Savasta M. Influence of the frequency parameter on extracellular glutamate and gamma-aminobutyric acid in substantia nigra and globus pallidus during electrical stimulation of subthalamic nucleus in rats. J Neurosci Res 2003;72:259-267.

53. Windels F, Bruet N, Poupard A, et al. Effects of high frequency stimulation of subthalamic nucleus on extracellular glutamate and GABA in substantia nigra and globus pallidus in the normal rat. Eur J Neurosci 2000;12:4141-4146.

54. Windels F, Carcenac C, Poupard A, Savasta M. Pallidal origin of GABA release within the substantia nigra pars reticulata during high-frequency stimulation of the subthalamic nucleus. J Neurosci 2005;25:5079-5086.

55. Boulet S, Lacombe E, Carcenac C, et al. Subthalamic stimulationinduced forelimb dyskinesias are linked to an increase in glutamate levels in the substantia nigra pars reticulata. J Neurosci 2006;26:10768-10776.

56. Ashby P, Paradiso G, Saint-Cyr JA, Chen R, Lang AE, Lozano AM. Potentials recorded at the scalp by stimulation near the human subthalamic nucleus. Clin Neurophysiol 2001;112:431437.

57. Sato F, Lavallée P, Levesque M, Parent A. Single-axon tracing study of neurons of the external segment of the globus pallidus in primate. J Comp Neurol 2000;417:17-31.

58. Hamani C, Saint-Cyr JA, Fraser J, Kaplitt M, Lozano AM. The subthalamic nucleus in the context of movement disorders. Brain 2004;127:4-20.

59. Plaha P, Ben-Shlomo Y, Patel NK, Gill SS. Stimulation of the caudal zona incerta is superior to stimulation of the subthalamic nucleus in improving contralateral parkinsonism. Brain 2006;129: 1732-1747.

60. Herzog J, Hamel W, Wenzelburger R, et al. Kinematic analysis of thalamic versus subthalamic neurostimulation in postural and intention tremor. Brain 2007;130:1608-1625.

61. Stover NP, Okun MS, Evatt ML, Raju DV, Bakay RA, Vitek JL. Stimulation of the subthalamic nucleus in a patient with Parkinson disease and essential tremor. Arch Neurol 2005;62:141-143.

62. Bruet N, Windels F, Carcenac C, et al. Neurochemical mechanisms induced by high frequency stimulation of the subthalamic nucleus: increase of extracellular striatal glutamate and GABA in normal and hemiparkinsonian rats. J Neuropathol Exp Neurol 2003;62:1228-1240.

63. Lee KH, Blaha CD, Harris BT, et al. Dopamine efflux in the rat striatum evoked by electrical stimulation of the subthalamic nucleus: potential mechanism of action in Parkinson's disease. Eur J Neurosci 2006;23:1005-1014.

64. Meissner W, Harnack D, Paul G, et al. Deep brain stimulation of subthalamic neurons increases striatal dopamine metabolism and induces contralateral circling in freely moving 6-hydroxydopamine-lesioned rats. Neurosci Lett 2002;328:105108.

65. Henning J, Koczan D, Glass A, et al. Deep brain stimulation in a rat model modulates TH, CaMKIIa and Homer1 gene expression. Eur J Neurosci 2007;25:239-250.

66. Lacombe E, Carcenac C, Boulet S, et al. High-frequency stimulation of the subthalamic nucleus prolongs the increase in striatal dopamine induced by acute 1-3,4-dihydroxyphenylalanine in dopaminergic denervated rats. Eur J Neurosci 2007;26:1670-1680.

67. Abosch A, Kapur S, Lang AE, et al. Stimulation of the subthalamic nucleus in Parkinson's disease does not produce striatal dopamine release. Neurosurgery 2003;53:1095-1102; discussion 1102-1105.

68. Hilker R, Voges J, Ghaemi M, et al. Deep brain stimulation of the subthalamic nucleus does not increase the striatal dopamine concentration in parkinsonian humans. Mov Disord 2003;18:41-48.

69. Strafella AP, Sadikot AF, Dagher A. Subthalamic deep brain stimulation does not induce striatal dopamine release in Parkinson's disease. Neuroreport 2003;14:1287-1289.

70. Parent A, Sato F, Wu Y, et al. Organization of the basal ganglia: the importance of axonal collateralization. Trends Neurosci 2000; 23(Suppl 10):S20-S27.

71. Cossette M, Levesque M, Parent A. Extrastriatal dopaminergic innervation of human basal ganglia. Neurosci Res 1999;34:5154.

72. Lavoie B, Smith Y, Parent A. Dopaminergic innervation of the basal ganglia in the squirrel monkey as revealed by tyrosine hydroxylase immunohistochemistry. J Comp Neurol 1989;289: 36-52.

73. Meissner W, Harnack D, Hoessle N, et al. High frequency stimulation of the entopeduncular nucleus has no effect on striatal dopaminergic transmission. Neurochem Int 2004;44:281-286.

74. Montgomery EB Jr, Baker KB. Mechanisms of deep brain stimulation and future technical developments. Neurol Res 2000;22: 259-266.

75. Vitek JL. Mechanisms of deep brain stimulation: excitation or inhibition. Mov Disord 2002;17 Suppl 3:S69-S72.

76. Garcia L, D'Alessandro G, Fernagut PO, Bioulac B, Hammond C. Impact of high-frequency stimulation parameters on the pattern of discharge of subthalamic neurons. J Neurophysiol 2005 ; 94:3662-3669.

77. Grill WM, Snyder AN, Miocinovic S. Deep brain stimulation creates an informational lesion of the stimulated nucleus. Neuroreport 2004; 15:1137-1140.

78. Rubin JE, Terman D. High frequency stimulation of the subthalamic nucleus eliminates pathological thalamic rhythmicity in a computational model. J Comput Neurosci 2004;16:211-235.

79. Schulte T, Brecht S, Herdegen T, Illert M, Mehdorn HM, Hamel $\mathrm{W}$. Induction of immediate early gene expression by high-frequency stimulation of the subthalamic nucleus in rats. Neuroscience 2006;138:1377-1385.

80. Stefani A, Lozano AM, Peppe A, et al. Bilateral deep brain stimulation of the pedunculopontine and subthalamic nuclei in severe Parkinson's disease. Brain 2007;130:1596-1607.

81. Pahapill PA, Lozano AM. The pedunculopontine nucleus and Parkinson's disease. Brain 2000;123:1767-1783.

82. Mazzone P, Lozano A, Stanzione $\mathrm{P}$, et al. Implantation of human pedunculopontine nucleus: a safe and clinically relevant target in Parkinson's disease. Neuroreport 2005;16:1877-1881.

83. Alterman RL, Shils JL, Miravite J, Tagliati M. Lower stimulation frequency can enhance tolerability and efficacy of pallidal deep brain stimulation for dystonia. Mov Disord 2007;22:366-368.

84. Tagliati M, Shils J, Sun C, Alterman R. Deep brain stimulation for dystonia. Expert Rev Med Devices 2004;1:33-41.

85. Lozano AM, Dostrovsky J, Chen R, Ashby P. Deep brain stimulation for Parkinson's disease: disrupting the disruption. Lancet Neurol 2002;1:225-231.

86. Bergman H, Wichmann T, Karmon B, DeLong MR. The primate subthalamic nucleus: II. Neuronal activity in the MPTP model of parkinsonism. J Neurophysiol 1994;72:507-520.

87. Magnin M, Morel A, Jeanmonod D. Single-unit analysis of the 
pallidum, thalamus and subthalamic nucleus in parkinsonian patients. Neuroscience 2000;96:549-564.

88. Brown P, Oliviero A, Mazzone P, Insola A, Tonali P, Di Lazzaro V. Dopamine dependency of oscillations between subthalamic nucleus and pallidum in Parkinson's disease. J Neurosci 2001; 21:1033-1038.

89. Magill PJ, Bolam JP, Bevan MD. Dopamine regulates the impact of the cerebral cortex on the subthalamic nucleus-globus pallidus network. Neuroscience 2001;106:313-330.

90. Plenz D, Kital ST. A basal ganglia pacemaker formed by the subthalamic nucleus and external globus pallidus. Nature 1999; 400:677-682.

91. Levy R, Ashby P, Hutchison WD, Lang AE, Lozano AM, Dostrovsky JO. Dependence of subthalamic nucleus oscillations on movement and dopamine in Parkinson's disease. Brain 2002; 125:1196-1209.

92. Brown P, Mazzone P, Oliviero A, et al. Effects of stimulation of the subthalamic area on oscillatory pallidal activity in Parkinson's disease. Exp Neurol 2004;188:480-490.

93. Mink JW. The basal ganglia: focused selection and inhibition of competing motor programs. Progress in neurobiology 1996;50: 381-425.

94. Perlmutter JS, Tempel LW, Black KJ, et al. MPTP induces dystonia and parkinsonism: clues to the pathophysiology of dystonia. Neurology 1997;49:1432-1438.

95. Brotchie P, Iansek R, Horne MK. Motor function of the monkey globus pallidus: 2. Cognitive aspects of movement and phasic neuronal activity. Brain 1991;114:1685-1702.

96. Bergman H, Feingold A, Nini A, et al. Physiological aspects of information processing in the basal ganglia of normal and parkinsonian primates. Trends Neurosci 1998;21:32-38.

97. Pessiglione M, Guehl D, Rolland AS, et al. Thalamic neuronal activity in dopamine-depleted primates: evidence for a loss of functional segregation within basal ganglia circuits. J Neurosci 2005;25:1523-1531.

98. Vitek JL, Ashe J, DeLong MR, et al. Altered somatosensory response properties of neurons in the 'motor' thalamus of MPTP treated parkinsonian monkeys. Soc Neurosci Abstr 1990: 16.425(abstract).

99. Leblois A, Meissner W, Bezard E, Bioulac B, Gross CE, Boraud T. Temporal and spatial alterations in GPi neuronal encoding might contribute to slow down movement in Parkinsonian monkeys. Eur J Neurosci 2006;24:1201-1208.

100. Byl NN, Merzenich MM, Jenkins WM. A primate genesis model of focal dystonia and repetitive strain injury: I. Learning-induced dedifferentiation of the representation of the hand in the primary somatosensory cortex in adult monkeys. Neurology 1996;47: $508-520$.

101. Lenz FA, Jaeger CJ, Seike MS, et al. Thalamic single neuron activity in patients with dystonia: dystonia-related activity and somatic sensory reorganization. J Neurophysiol 1999;82:23722392.

102. Lenz FA, Suarez JI, Metman LV, et al. Pallidal activity during dystonia: somatosensory reorganisation and changes with severity. J Neurol Neurosurg Psychiatry 1998;65:767-770.

103. Vitek JL, Chockkan V, Zhang JY, et al. Neuronal activity in the basal ganglia in patients with generalized dystonia and hemiballismus. Ann Neurol 1999;46:22-35.

104. Hutchison WD, Lang AE, Dostrovsky JO, Lozano AM. Pallidal neuronal activity: implications for models of dystonia. Ann Neurol 2003;53:480-488.

105. Butson CR, McIntyre CC. Tissue and electrode capacitance reduce neural activation volumes during deep brain stimulation. Clin Neurophysiol 2005;116:2490-2500.

106. Kaas JH. Plasticity of sensory and motor maps in adult mammals. Annu Rev Neurosci 1991;14:137-167.

107. Jenkins WM, Merzenich MM. Reorganization of neocortical representations after brain injury: a neurophysiological model of the bases of recovery from stroke. Prog Brain Res 1987;71:249-266.

108. Temperli P, Ghika J, Villemure JG, Burkhard PR, Bogousslavsky J, Vingerhoets FJ. How do parkinsonian signs return after discontinuation of subthalamic DBS? Neurology 2003;60:78-81.
109. Yianni J, Bain PG, Gregory RP, et al. Post-operative progress of dystonia patients following globus pallidus internus deep brain stimulation. Eur J Neurol 2003;10:239-247.

110. Gross C, Rougier A, Guehl D, Boraud T, Julien J, Bioulac B. High-frequency stimulation of the globus pallidus internalis in Parkinson's disease: a study of seven cases. J Neurosurg 1997; 87:491-498.

111. Hristova A, Lyons K, Tröster AI, Pahwa R, Wilkinson SB, Koller WC. Effect and time course of deep brain stimulation of the globus pallidus and subthalamus on motor features of Parkinson's disease. Clin Neuropharmacol 2000;23:208-211.

112. Krauss JK, Yianni J, Loher TJ, Aziz TZ. Deep brain stimulation for dystonia. J Clin Neurophysiol 2004;21:18-30.

113. Houeto JL, Karachi C, Mallet L, et al. Tourette's syndrome and deep brain stimulation. J Neurol Neurosurg Psychiatry 2005;76: 992-995.

114. Shen KZ, Zhu ZT, Munhall A, Johnson SW. Synaptic plasticity in rat subthalamic nucleus induced by high-frequency stimulation. Synapse 2003;50:314-319.

115. Titcombe MS, Glass L, Guehl D, Beuter A. Dynamics of Parkinsonian tremor during deep brain stimulation. Chaos 2001;11: $766-773$.

116. Lozano A. Deep brain stimulation: challenges to integrating stimulation technology with human neurobiology, neuroplasticity, and neural repair. J Rehabil Res Dev 2001;38:x-xix.

117. Muta D, Goto S, Nishikawa S, et al. Bilateral pallidal stimulation for idiopathic segmental axial dystonia advanced from Meige syndrome refractory to bilateral thalamotomy. Mov Disord 2001; 16:774-777.

118. Trottenberg T, Meissner W, Kabus C, et al. Neurostimulation of the ventral intermediate thalamic nucleus in inherited myoclonusdystonia syndrome [Erratum in: Mov Disord 2001;16:1204]. Mov Disord 2001;16:769-771.

119. Haberler C, Alesch F, Mazal PR, et al. No tissue damage by chronic deep brain stimulation in Parkinson's disease. Ann Neurol 2000;48:372-376.

120. Nielsen MS, Bjarkam CR, Sørensen JC, Bojsen-Møller M, Sunde NA, Østergaard K. Chronic subthalamic high-frequency deep brain stimulation in Parkinson's disease: a histopathological study. Eur J Neurol 2007;14:132-138.

121. Kultas-Ilinsky K, De Boom T, Ilinsky IA. Synaptic reorganization in the feline ventral anterior thalamic nucleus induced by lesions in the basal ganglia. Exp Neurol 1992;116:312-329.

122. Ambardekar AV, Surin A, Parts K, Ilinsky IA, Kultas-Ilinsky K. Distribution and binding parameters of $\mathrm{GABA}_{\mathrm{A}}$ receptors in the thalamic nuclei of Macaca mulatta and changes caused by lesioning in the globus pallidus and reticular thalamic nucleus. Neuroscience 2003;118:1033-1043.

123. Calon F, Morissette M, Rajput AH, Hornykiewicz O, Bédard PJ, Di Paolo T. Changes of GABA receptors and dopamine turnover in the postmortem brains of parkinsonians with levodopa-induced motor complications. Mov Disord 2003;18:241-253.

124. Benabid AL, Piallat B, Wallace B, et al. Might deep brain stimulation of the subthalamic nucleus be neuroprotective in patients with Parkinson's disease? Thalamus Relat Syst 2003;2:95-102.

125. Wallace BA, Ashkan K, Heise CE, et al. Survival of midbrain dopaminergic cells after lesion or deep brain stimulation of the subthalamic nucleus in MPTP-treated monkeys. Brain 2007;130: $2129-2145$.

126. Maesawa S, Kaneoke Y, Kajita Y, et al. Long-term stimulation of the subthalamic nucleus in hemiparkinsonian rats: neuroprotection of dopaminergic neurons. J Neurosurg 2004;100:679-687.

127. Piallat B, Benazzouz A, Benabid AL. Subthalamic nucleus lesion in rats prevents dopaminergic nigral neuron degeneration after striatal 6-OHDA injection: behavioural and immunohistochemical studies. Eur J Neurosci 1996;8:1408-1414.

128. Lyons KE, Pahwa R. Deep brain stimulation and tremor. Neurotherapeutics 2008;5:331-338.

129. Limousin P, Martinez-Torres I. Deep brain stimulation for Parkinson's disease. Neurotherapeutics 2008;5:309-319.

130. Ostrem JL, Starr PA. Treatment of dystonia with deep brain stimulation. Neurotherapeutics 2008;5:320-330. 
131. Ackermans L, Temel Y, Visser-Vandewalle V. Deep brain stimulation in Tourette's syndrome. Neurotherapeutics 2008;5:339344.

132. Obeso J, Guridi J, Rodriguez-Oroz MC, Krack P, Kumar R, Lang AE; Deep Brain Stimulation for Parkinson's Disease Study Group. Deep-brain stimulation of the subthalamic nucleus or the pars interna of the globus pallidus in Parkinson's disease. N Engl J Med 2001;345:956-963.

133. Drouot X, Oshino S, Jarraya B, et al. Functional recovery in a primate model of Parkinson's disease following motor cortex stimulation. Neuron 2004;44:769-778.

134. Sun B, Li D, Sun C, et al. Target selection for primary dystonia deep brain stimulation: GPi or STN. Presented at 2003 meeting of the American Society for Stereotactic and Functional Neurosurgery, New York, 18-21 May 2003.

135. Chou KL, Hurtig HI, Jaggi JL, Baltuch GH. Bilateral subthalamic nucleus deep brain stimulation in a patient with cervical dystonia and essential tremor. Mov Disord 2005;20:377-380.

136. Vercueil L, Pollak P, Fraix V, et al. Deep brain stimulation in the treatment of severe dystonia. J Neurol 2001;248:695-700.

137. Lyons KE, Pahwa R. Deep brain stimulation and essential tremor. J Clin Neurophysiol 2004;21:2-5.

138. Diamond A, Shahed J, Jankovic J. The effects of subthalamic nucleus deep brain stimulation on parkinsonian tremor. J Neurol Sci 2007;260:199-203.

139. Servello D, Porta M, Sassi M, Brambilla A, Robertson MM. Deep brain stimulation in 18 patients with severe Gilles de la Tourette Syndrome refractory to treatment: the surgery and stimulation. J Neurol Neurosurg Psychiatry 2008;79:136-142.

140. Visser-Vandewalle V, Temel Y, Boon P, et al. Chronic bilateral thalamic stimulation: a new therapeutic approach in intractable Tourette syndrome: report of three cases. J Neurosurg 2003:99: 1094-1100.

141. Diederich NJ, Kalteis K, Stamenkovic M, et al. Efficient internal pallidal stimulation in Gilles de la Tourette syndrome: a case report. Mov Disord 2005;20:1496-1499.

142. Shahed J, Poysky J, Kenney C, Simpson K, Jankovic J. GPi deep brain stimulation for Tourette syndrome improves tics and psychiatric comorbidities. Neurology 2007;68:159-160.

143. Flaherty AW, Williams ZM, Amirnovin R, et al. Deep brain stimulation of the anterior internal capsule for the treatment of Tourette syndrome: technical case report. Neurosurgery 2005;57: E403; discussion E403.

144. Devos D, Derambure P, Bourriez JL, et al. Influence of internal globus pallidus stimulation on motor cortex activation pattern in Parkinson's disease. Clin Neurophysiol 2002;113:1110-1120.

145. Devos D, Labyt E, Derambure P, et al. Subthalamic nucleus stimulation modulates motor cortex oscillatory activity in Parkinson's disease. Brain 2004;127:408-419.

146. Limousin P, Greene J, Pollak P, Rothwell J, Benabid AL, Frackowiak R. Changes in cerebral activity pattern due to subthalamic nucleus or internal pallidum stimulation in Parkinson's disease. Ann Neurol 1997;42:283-291.

147. Ilinsky IA, Jouandet ML, Goldman-Rakic PS. Organization of the nigrothalamocortical system in the rhesus monkey. J Comp Neurol 1985;236:315-330.

148. Hoover JE, Strick PL. The organization of cerebellar and basal ganglia outputs to primary motor cortex as revealed by retrograde transneuronal transport of herpes simplex virus type 1. J Neurosci 1999;19:1446-1463.

149. Hoover JE, Strick PL. Multiple output channels in the basal ganglia. Science 1993;259:819-821.

150. Nambu A, Yoshida S, Jinnai K. Discharge patterns of pallidal neurons with input from various cortical areas during movement in the monkey. Brain Res 1990;519:183-191.
151. Yoshida S, Nambu A, Jinnai K. The distribution of the globus pallidus neurons with input from various cortical areas in the monkeys. Brain Res 1993;611:170-174.

152. Grafton ST, Turner RS, Desmurget M, et al. Normalizing motorrelated brain activity: subthalamic nucleus stimulation in Parkinson disease. Neurology 2006;66:1192-1199.

153. Bejjani B, Damier P, Arnulf I, et al. Pallidal stimulation for Parkinson's disease: two targets? Neurology 1997;49: 1564-1569.

154. Krack P, Pollak P, Limousin P, et al. Opposite motor effects of pallidal stimulation in Parkinson's disease. Ann Neurol 1998;43: 180-192.

155. Yelnik J, Damier P, Bejjani BP, et al. Functional mapping of the human globus pallidus: contrasting effect of stimulation in the internal and external pallidum in Parkinson's disease. Neuroscience 2000;101:77-87.

156. Xu W, Miocinovic S, Zhang J, Russo GS, McIntyre CC, Vitek JL. Dissociation of motor symptoms during deep brain stimulation of the subthalamic nucleus in the region of the internal capsule. Soc Neurosci Abstr 2007.693.17(abstract).

157. Vitek JL, Bakay RA, Hashimoto T, et al. Microelectrode-guided pallidotomy: technical approach and its application in medically intractable Parkinson's disease. J Neurosurg 1998;88:1027-1043.

158. Ashby P, Strafella A, Dostrovsky JO, Lozano A, Lang AE. Immediate motor effects of stimulation through electrodes implanted in the human globus pallidus. Stereotact Funct Neurosurg 1998;70:1-18.

159. Butson CR, Cooper SE, Henderson JM, McIntyre CC. Patientspecific analysis of the volume of tissue activated during deep brain stimulation. Neuroimage 2007;34:661-670.

160. Moro E, Poon YY, Lozano AM, Saint-Cyr JA, Lang AE. Subthalamic nucleus stimulation: improvements in outcome with reprogramming. Arch Neurol 2006;63:1266-1272.

161. Funkiewiez A, Ardouin C, Krack P, et al. Acute psychotropic effects of bilateral subthalamic nucleus stimulation and levodopa in Parkinson's disease. Mov Disord 2003;18:524-530.

162. Bejjani BP, Damier P, Arnulf I, et al. Transient acute depression induced by high-frequency deep-brain stimulation. N Engl J Med 1999;340:1476-1480.

163. Middleton FA, Strick PL. Anatomical evidence for cerebellar and basal ganglia involvement in higher cognitive function. Science 1994;266:458-461.

164. Middleton FA, Strick PL. Basal ganglia and cerebellar loops: motor and cognitive circuits. Brain Res Brain Res Rev 2000;31: $236-250$.

165. Frank MJ, Samanta J, Moustafa AA, Sherman SJ. Hold your horses: impulsivity, deep brain stimulation, and medication in parkinsonism. Science 2007;318:1309-1312.

166. Middleton FA, Strick PL. The temporal lobe is a target of output from the basal ganglia. Proc Natl Acad Sci U S A 1996;93: 8683-8687.

167. Braak H, Ghebremedhin E, Rüb U, Bratzke H, Del Tredici K. Stages in the development of Parkinson's disease-related pathology. Cell Tiss Res 2004;318:121-134.

168. Parent M, Parent A. Axonal collateralization in primate basal ganglia and related thalamic nuclei. Thalamus Relat Syst 2002; 2:71-86.

169. Alexander GE, DeLong MR, Strick PL. Parallel organization of functionally segregated circuits linking basal ganglia and cortex. Annu Rev Neurosci 1986;9:357-381.

170. Grips E, Blahak C, Capelle HH, et al. Patterns of reoccurrence of segmental dystonia after discontinuation of deep brain stimulation. J Neurol Neurosurg Psychiatry 2007;78:318-320. 